\title{
Not Known if PDGFRA Mutation Analysis Was Performed
}

National Cancer Institute

\section{Source}

National Cancer Institute. Not Known if PDGFRA Mutation Analysis Was Performed. NCI

Thesaurus. Code C160463.

An indication that it is not known whether PDGFRA mutation analysis was performed during the study. 